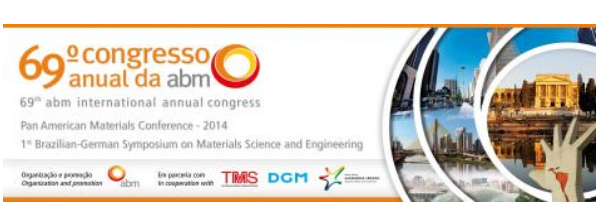

Tema: Soldagem

\title{
EFEITO DE TRATAMENTO TÉRMICO PÓS-SOLDAGEM NAS PROPRIEDADES MECÂNICAS DE JUNTAS SOLDADAS DE AÇO FUNDIDO DE ALTA RESISTÊNCIA MECÂNICA*
}

\author{
Elias Macedo de Oliveira ${ }^{1}$ \\ Jorge Carlos Ferreira Jorge ${ }^{2}$ \\ Luís Felipe Guimarães de Souza²
}

\section{Resumo}

Este trabalho tem por objetivo realizar a avaliação das propriedades mecânicas da zona termicamente afetada (ZTA) de junta soldada de aço fundido de alta resistência, obtida pelo processo eletrodo revestido, analisando o efeito da variação do tempo de tratamento térmico pós-soldagem. Foram soldadas juntas multipasses para avaliação de propriedades mecânicas de um aço fundido de alta resistência mecânica, com preaquecimento de $200^{\circ} \mathrm{C}$, corrente contínua, posição plana e aporte térmico médio de $1,5 \mathrm{~kJ} / \mathrm{mm}$. Após a soldagem, realizaram-se ensaios mecânicos e metalográficos em corpos-de-prova retirados da ZTA e metal base, tanto na condição de como soldado quanto após tratamentos térmicos pós-soldagem. Os tratamentos térmicos pós-soldagem foram realizados à $600^{\circ} \mathrm{C}$, por 1,2 e 3 horas, visando avaliar o efeito destes tratamentos nas propriedades da ZTA. Os resultados mostraram que as propriedades mecânicas não apresentaram diferenças significativas em relação ao metal base com os tratamentos térmicos realizados, propiciando resultados satisfatórios em relação aos requisitos da norma IACS W22 Grau R4.

Palavras-chave: Aço fundido; Zona termicamente afetada; Propriedades mecânicas; Tratamento térmico pós-soldagem.

\section{EFFECT OF POST WELD HEAT TREATMENT ON THE MECHANICAL PROPERTIES OF HIGH STRENGTH CAST STEEL WELDED JOINTS}

\begin{abstract}
The mechanical properties of the heat affected zone (HAZ) of the high strength cast steel welded by shielded metal arc welding process were investigated in order to evaluate the time variation effect of the postweld heat treatment. Welded joints were performed by SMAW process using a preheat of $200^{\circ} \mathrm{C}$, direct current, flat position and a nominal heat input of $1,5 \mathrm{~kJ} / \mathrm{mm}$. After welding, mechanical tests and metallographic examination were conducted in specimens removed from the heat affected zone and base metal, both in as welded condition and heat treated conditions. The post weld heat treatments were conducted at $600^{\circ} \mathrm{C}$ for 1,2 and 3 hours, following cooling air. The results showed that the mechanical properties did not present great changes in relation to the base metal, reaching satisfactory results according to the requirements of the IACS W22 Grade R4 steel.
\end{abstract}

Keywords: Cast steel; Heat affected zone; Mechanical properties; Post weld heat treatment.

Eng. Mecânico, Mestrando, PEMM, CEFET-RJ, Rio de Janeiro, RJ, Brasil.

Eng. Metalúrgico, M.Sc. DSc., Professor, PEMM, CEFET-RJ, Rio de Janeiro, RJ, Brasil.

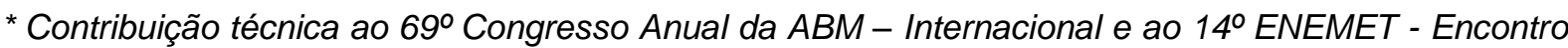
Nacional de Estudantes de Engenharia Metalúrgica, de Materiais e de Minas,21 a 25 de julho de 2014, São Paulo, SP, Brasil.
} 


\section{INTRODUÇÃO}

O aumento das atividades marítimas para exploração de petróleo, têm exigido maiores volumes de fornecimento de materiais de alta resistência para atendimento da demanda das necessidades de operações de exploração e produção de águas profundas.

Como a grande parte das unidades para operação em águas profundas são constituídas de plataformas semi-submersíveis [1], as linhas de ancoragem e seus componentes tomam importância fundamental, no aspecto de seleção e manutenção dos materiais envolvidos.

Neste aspecto, embora sempre seja desejável a utilização de materiais forjados em equipamentos de ligação devido ao melhor desempenho em fadiga [2], nem sempre é possível atender esta necessidade, não somente por questões de fornecimento, como também por questões técnicas, devido à geometrias complexas dos componentes. De fato, vários são os componentes de uma linha de ancoragem que apresentam projeto de difícil fabricação em forjado [3] com preço e prazo competitivos (Figura 1).

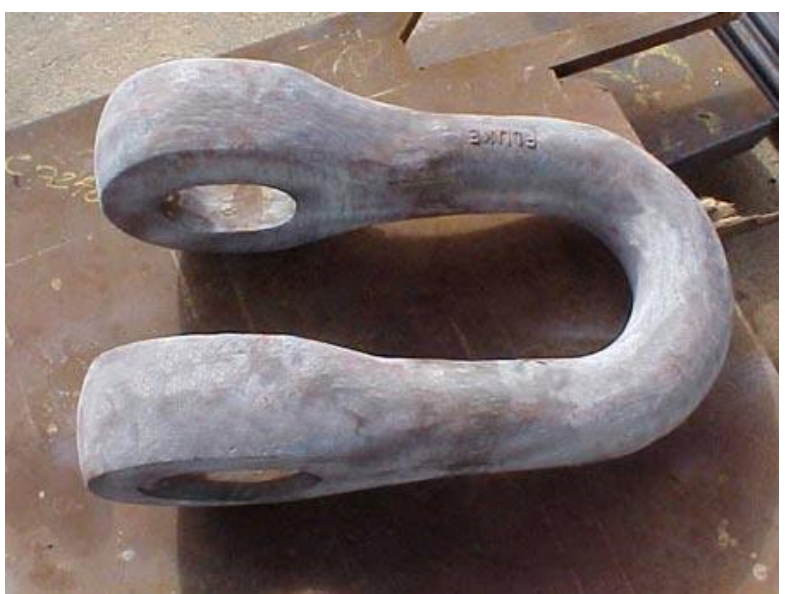

Manilha de âncora

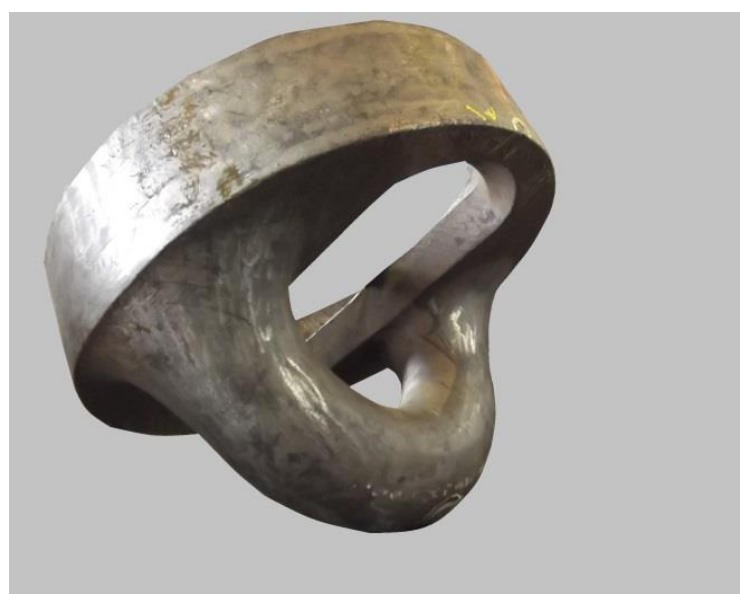

Olhal de torpedo de ancoragem

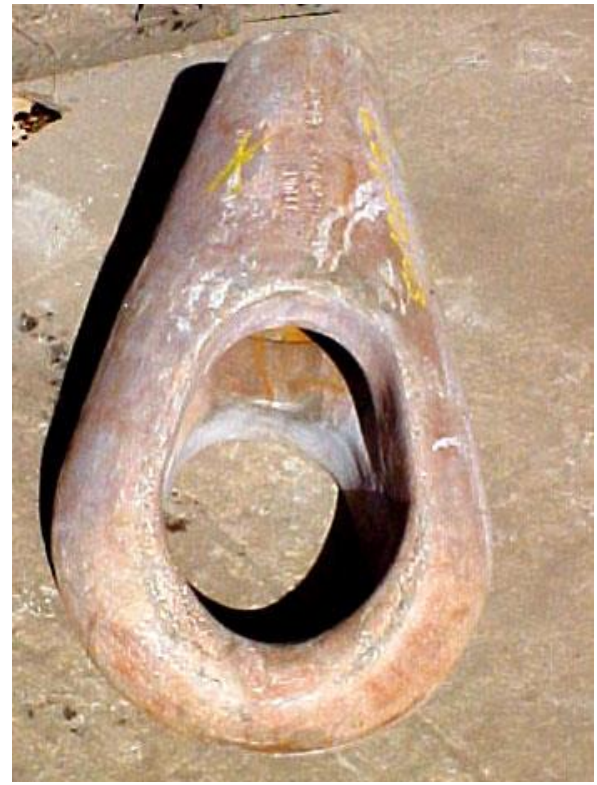

Soquete tipo pera

Figura 1. Exemplos de equipamentos de linhas de ancoragem com geometria complexa.

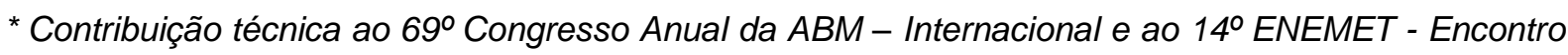
Nacional de Estudantes de Engenharia Metalúrgica, de Materiais e de Minas,21 a 25 de julho de 2014, São Paulo, SP, Brasil.
} 


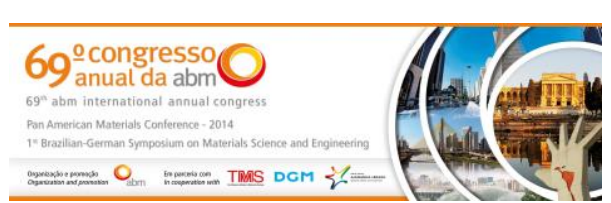

Desta forma, os aços fundidos ainda são utilizados nesta área de atuação e, pelo fato de apresentarem defeitos de fabricação que, por vezes, podem inviabilizar a continuidade de fornecimento do equipamento, faz-se necessário um estudo criterioso da possibilidade da execução de reparos seguros por soldagem, com o intuito de evitar o sucateamento prematuro destes equipamentos, mas ao mesmo tempo, garantir que o reparo não interfira negativamente na operação segura de todo o sistema.

Neste aspecto, realizou-se um extenso programa de pesquisas para avaliar esta questão [4-13], o qual permitiu obter dados experimentais que evidenciassem que a soldagem não compromete as propriedades de aços fundidos utilizados nestas aplicações.

No caso de componentes para ancoragem de plataformas, existem regras específicas para materiais adequados de acordo com os requisitos das Sociedades Classificadoras Navais [14-16]. Dependendo da aplicação as regras específicas podem levar a definição de requisitos extremamente complexos, visto haver na maior parte dos casos a necessidade de se associar elevadas resistências mecânicas com um alto padrão de tenacidade ao impacto.

A Tabela 1 mostra as propriedades mecânicas especificadas para diversos tipos de aços segundo a norma IACS W22 [16], com destaque para o aço grau R4, com ampla utilização em amarras e acessórios de ancoragem de plataformas de petróleo offshore. Este nível de exigência torna a soldagem destes componentes um grande desafio em termos da definição do procedimento de soldagem mais adequado.

Tabela 1. Propriedades mecânicas dos aços segundo a norma IACS W22 [16]

\begin{tabular}{c|c|c|c|c|c}
\hline Grau & LE $(\mathrm{MPa})$ & $\mathrm{LR}(\mathrm{MPa})$ & $\mathrm{Al}(\%)$ & $\mathrm{RA}(\%)$ & $\mathrm{E}_{\mathrm{cv}}$ à $-20^{\circ} \mathrm{C}(\mathrm{J})$ \\
\hline R3 & 410 & 690 & 17 & 50 & 40 \\
\hline R3S & 490 & 770 & 15 & 50 & 45 \\
\hline R4 & 580 & 860 & 12 & $50\left(35^{*}\right)$ & 50 \\
\hline R4S & 700 & 960 & 12 & 50 & 56 \\
\hline R5 & 760 & 1000 & 12 & 50 & 58
\end{tabular}

Obs.: LE - limite de escoamento; LR - limite de resistência; $A /$ - alongamento;

$R A$ - redução de área; $E_{c V}$ - energia Charpy-V.

$\left(^{\star}\right)$ Para aços fundidos.

Em trabalho anterior [13], onde se avaliou a viabilidade técnica da execução de soldagem de reparo em aço fundido de aço Grau R4, foi possível evidenciar que é viável a execução da soldagem de reparo com propriedades mecânicas adequadas, desde que se realize um tratamento térmico de alívio de tensões posterior à soldagem, não somente para o alívio das tensões residuais, quanto para adequação das propriedades mecânicas da junta soldada. Este trabalho teve importância para criar evidências experimentais que atestem a possibilidade de soldagem nestes aços, contribuindo para um melhor entendimento dos efeitos do ciclo térmico de soldagem nas propriedades mecânicas desse material, o qual ainda não tinha sido objeto de estudo pela literatura.

O presente trabalho dá continuidade e complementa este estudo, analisando o comportamento das propriedades da ZTA do aço Grau R4 após a variação do tempo de tratamento térmico, de forma a tornar possível uma definição do procedimento de reparo mais adequado para este material.

\footnotetext{
* Contribuição técnica ao 69ำ Congresso Anual da ABM - Internacional e ao 14ํㅡㄹ ENEMET - Encontro Nacional de Estudantes de Engenharia Metalúrgica, de Materiais e de Minas,21 a 25 de julho de 2014, São Paulo, SP, Brasil.
} 


\section{MATERIAIS E MÉTODOS}

\subsection{Materiais}

Realizou-se o estudo utilizando como consumível um eletrodo revestido de 4,0mm de diâmetro da classe AWS E12018M e como metal base um aço fundido do tipo R4 fornecido por um fabricante nacional. A Tabela 2 mostra a composição química dos materiais utilizados, obtida por análise realizada através de espectrometria de emissão ótica.

Tabela 2. Composição química do material utilizado (\% em peso)

\begin{tabular}{c|c|c|c|c|c|c|c|c|c|c}
\hline Material & $\mathrm{C}$ & $\mathrm{Mn}$ & $\mathrm{Si}$ & $\mathrm{Cr}$ & $\mathrm{Ni}$ & $\mathrm{Mo}$ & $\mathrm{P}$ & $\mathrm{S}$ & $\mathrm{V}$ & $\mathrm{Ceq}\left({ }^{*}\right)$ \\
\hline $\begin{array}{c}\text { Metal de } \\
\text { Solda }\end{array}$ & 0,06 & 1,34 & 0,41 & 0,84 & 2,38 & 0,64 & 0,015 & 0,005 & 0,002 & 0,74 \\
\hline Metal Base & 0,19 & 0,78 & 0,39 & 0,64 & 2,58 & 0,33 & 0,007 & 0,009 & 0,005 & 0,69 \\
\hline
\end{tabular}

O aço fundido tipo R4 foi retirado de uma manilha de âncora (Figura 2), de modo a reproduzir as condições reais de operação de reparo em campo. Esta condição é garantida após a realização do teste de "carga de prova" de 1400tonf. (Figura 2).

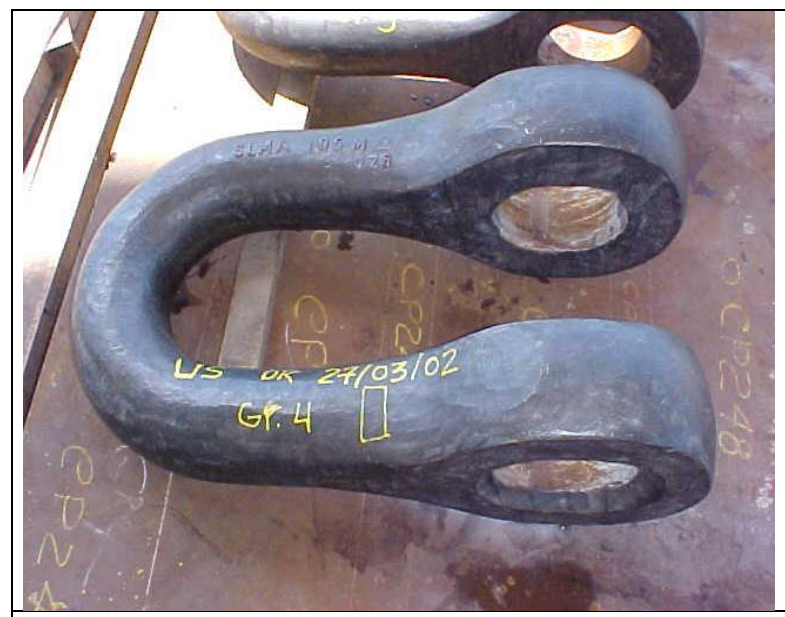

(a)

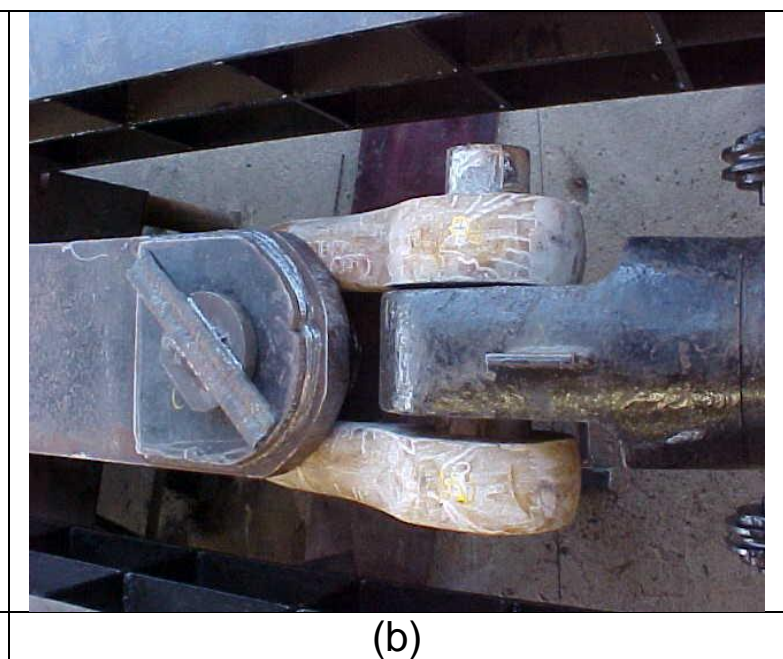

(b)

Figura 2. (a) Manilha de âncora para amarra de 120mm. (b) Montagem do teste de "carga de prova".

A Tabela 3 mostra as propriedades mecânicas do aço fundido R4 utilizado.

Tabela 3. Propriedades mecânicas do aço fundido R4.

\begin{tabular}{c|c|c|c|c|c}
\hline MATERIAL & LE(MPa) & LR(MPa) & Al(\%) & RA(\%) & $\begin{array}{c}\text { Energia Absorvida (J) } \\
\left(-20^{\circ} \mathrm{C}\right)\end{array}$ \\
\hline Manilha & 860 & 945 & 12,4 & 51,9 & 89,0 \\
\hline Mínimo R4 [16] & 580 & 860 & 12,0 & 35,0 & 50,0 \\
\hline
\end{tabular}

\subsection{Soldagem dos Corpos-de-prova}

Para a avaliação da junta soldada de aço fundido R4, realizou-se a preparação para soldagem através de corte da manilha por serra mecânica e preparação do chanfro por usinagem.

A junta foi preparada na forma de um tarugo com $150 \mathrm{~mm}$ de diâmetro, com chanfro em $\mathrm{X}$ de $50^{\circ}$ e com abertura na raiz de $4,0 \mathrm{~mm}$. A junta foi inicialmente preaquecida à

\footnotetext{
* Contribuição técnica ao $69^{\circ}$ Congresso Anual da ABM - Internacional e ao 14ํㅡㄹ ENEMET - Encontro Nacional de Estudantes de Engenharia Metalúrgica, de Materiais e de Minas,21 a 25 de julho de 2014, São Paulo, SP, Brasil.
} 


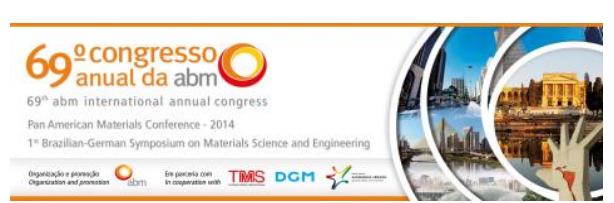

temperatura de $200^{\circ} \mathrm{C}$ e posteriormente realizou-se a soldagem multipasses, com eletrodos de 4,0 mm de diâmetro, na posição plana, corrente de 184 a 192 A, voltagem de (22 a 29 Volts), com aporte térmico médio de $1,5 \mathrm{~kJ} / \mathrm{mm}$, sendo realizados 233 passes de soldagem.

\subsection{Tratamentos Térmicos Pós Soldagem (TTPS)}

Após a soldagem, realizaram-se tratamentos térmicos consistindo de aquecimento à $600^{\circ} \mathrm{C}$ por 1,2 e 3 horas, sendo estas condições comparadas à condição da junta como soldada.

\subsection{Ensaios Mecânicos e Metalográficos}

Foram removidos corpos-de-prova transversais ao cordão de solda para ensaios de tração, impacto Charpy-V, dureza e metalográficos.

Os ensaios de tração foram realizados à temperatura ambiente, para avaliação da resistência mecânica da junta soldada, sendo realizados 2 ensaios para cada condição analisada.

Os ensaios de impacto Charpy- $V$ foram realizados à temperatura de $-20^{\circ} \mathrm{C}$, em corpos-de-prova normalizados $(10 \times 10 \times 55 \mathrm{~mm})$ e retirados a $2 \mathrm{~mm}$ da superfície da junta, sendo realizados 3 ensaios para cada condição analisada. $O$ entalhe foi posicionado no plano da espessura, nas posições relativas à linha de fusão (LF), 1LF, 3LF, 5LF e metal base. De modo a ser possível o posicionamento do entalhe integralmente na ZTA, estes foram inseridos de forma paralela ao ângulo do chanfro, como mostrado na Figura 3.

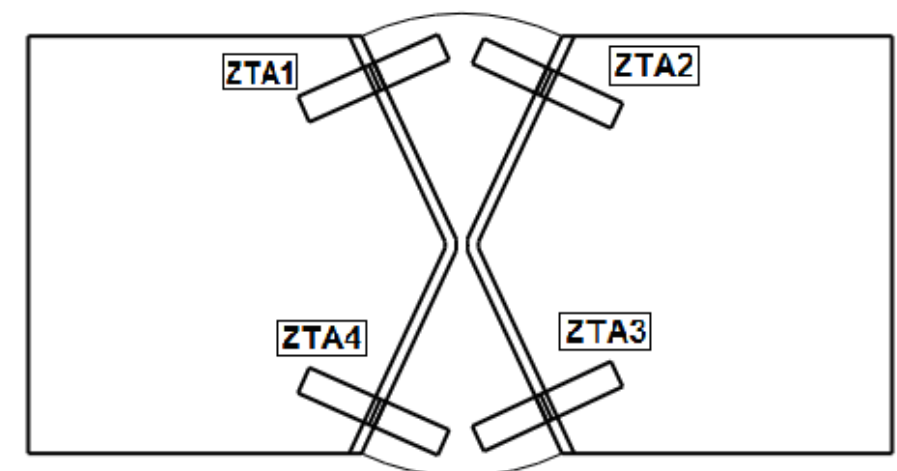

Figura 3. Detalhe do posicionamento do entalhe do corpo-de-prova Charpy-V.

Os ensaios de microdureza Vickers consistiram da varredura de dureza com aplicação de carga de 500 gf. em corpos-de-prova de prova de impacto Charpy-V. Realizou-se ensaio macrográfico da junta soldada, em amostra previamente preparada por lixamento e posterior ataque químico com nital $10 \%$.

Foram preparadas amostras metalográficas para análise por microscopia eletrônica de varredura (MEV) com ataque de nital $2 \%$, para identificação das microestruturas presentes na ZTA, nas diferentes condições de análise. A preparação das amostras consistiu de lixamento com lixas de granulometria 100, 220, 320, 400 e 600 e posterior polimento em pasta de diamante de 6 , 3 e $1 \mu \mathrm{m}$.

\footnotetext{
* Contribuição técnica ao $69^{\circ}$ Congresso Anual da ABM - Internacional e ao 14ํㅡㄹ ENEMET - Encontro Nacional de Estudantes de Engenharia Metalúrgica, de Materiais e de Minas,21 a 25 de julho de 2014, São Paulo, SP, Brasil.
} 


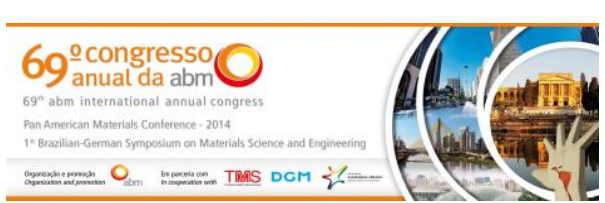

\section{RESULTADOS}

\subsection{Ensaios de Tração da Junta Soldada}

A Tabela 4 mostra os resultados dos ensaios de tração transversal realizados nas quatro condições de análise, onde se verifica que em todas as condições a fratura ocorreu no metal base com limite de resistência superior acima do mínimo exigido para o aço R4, embora deva ser destacado que as condições TTPS-2h e TTPS-3h apresentam resultados muito próximos deste mínimo.

Tabela 4. Resultados dos ensaios de tração.

\begin{tabular}{c|c|c|c|c}
\hline CondiçãolLR(MPa) & CP1 & CP2 & MÉDIA & Fratura \\
\hline Como soldado & 920 & 900 & 910 & Metal base \\
\hline TTPS - 1h & 912 & 899 & 905 & Metal base \\
\hline TTPS - 2h & 869 & 859 & 864 & Metal base \\
\hline TTPS - 3h & 865 & 861 & 863 & Metal base \\
\hline Mínimo R4 [16] & 860 & 860 & 860 & - \\
\hline
\end{tabular}

Onde: $L R$ - limite de resistência

\subsection{Ensaios de Impacto da Junta Soldada}

A figura 4 mostra os resultados dos ensaios de impacto realizados nas quatro condições de análise, onde se verificam as seguintes características:

a) Todas as condições de análise apresentaram-se superiores ao mínimo exigido para o aço R4 e;

b) Os valores de energia absorvida para as diferentes condições de análise apresentaram pequena variação com o tempo de tratamento.

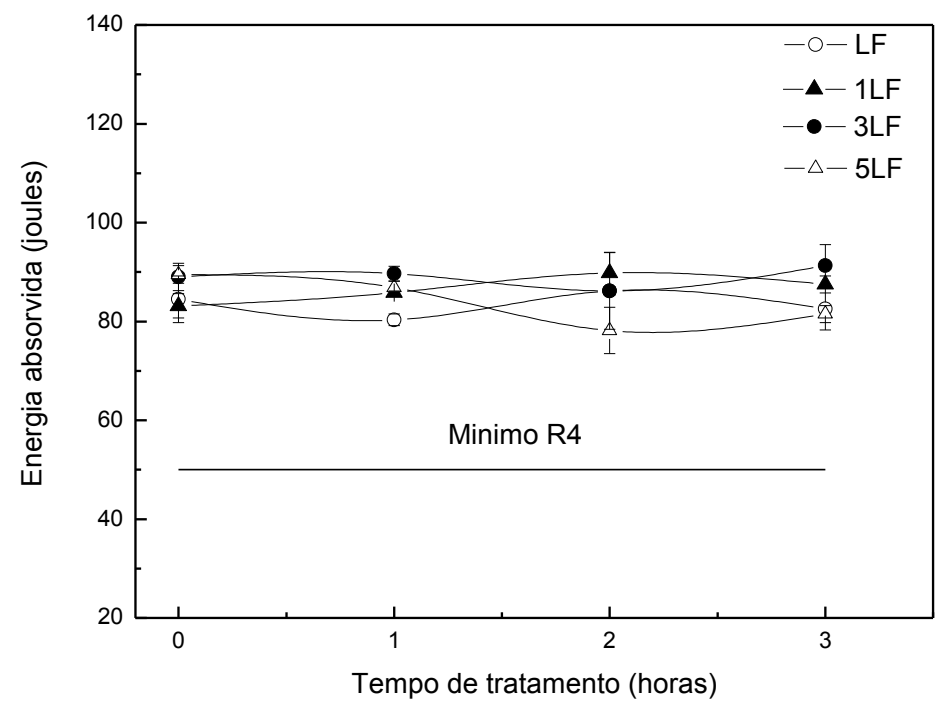

Figura 4. Variação da energia absorvida à $-20^{\circ} \mathrm{C}$ com o tempo de tratamento térmico.

A Figura 5 mostra os resultados dos ensaios de impacto realizados para o TTPS realizado após 1 hora, evidenciando não haver mudanças significativas para as diferentes posições de teste na ZTA em relação ao resultado original do metal base.

\footnotetext{
* Contribuição técnica ao 69ำ Congresso Anual da ABM - Internacional e ao 14ํㅡㄹ ENEMET - Encontro Nacional de Estudantes de Engenharia Metalúrgica, de Materiais e de Minas,21 a 25 de julho de 2014, São Paulo, SP, Brasil.
} 

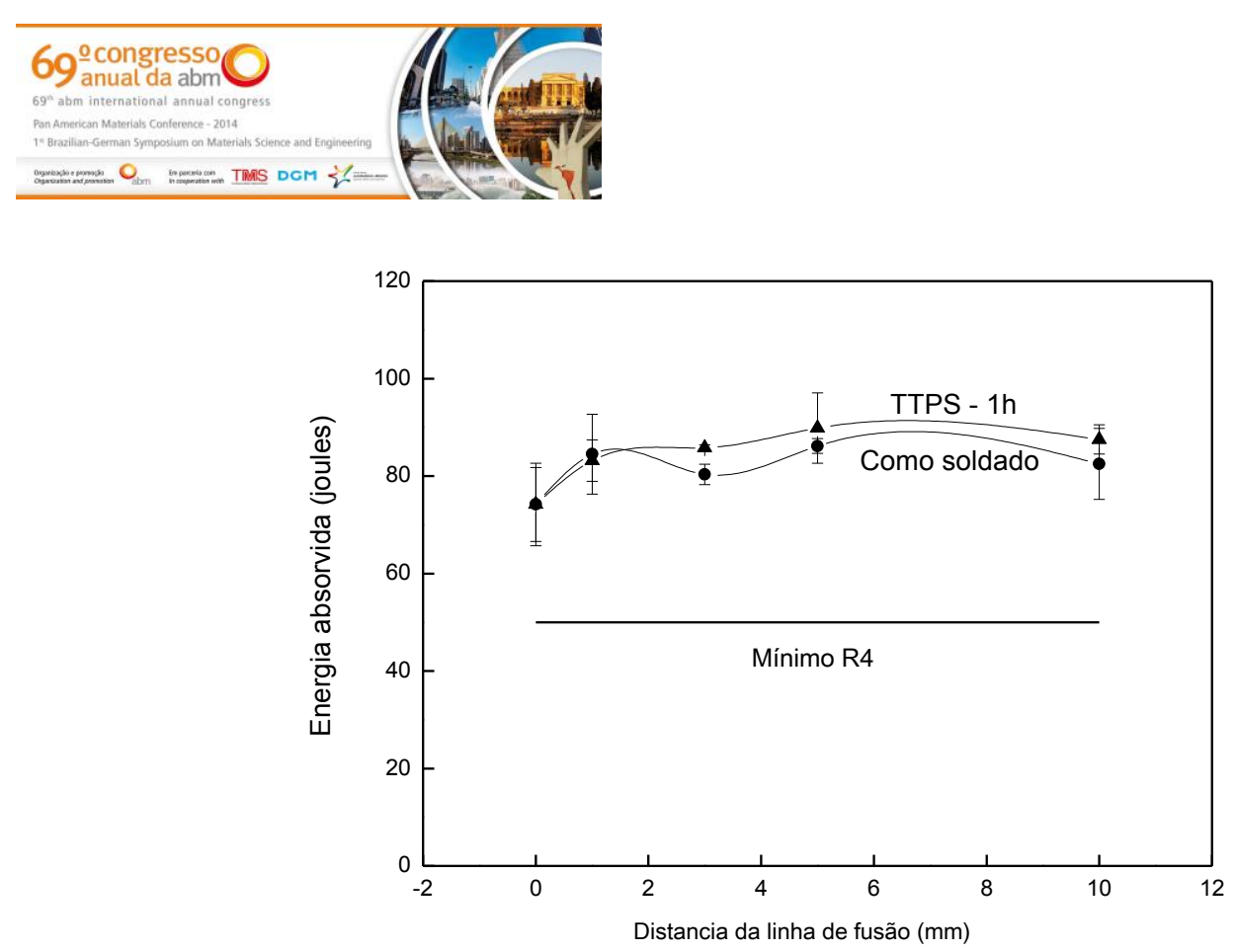

Figura 5. Energia absorvida à -20ำ para diferentes posições da ZTA após TTPS - 1h.

\subsection{Ensaios de Dureza da Junta Soldada}

A Figura 6 mostra os resultados dos ensaios de microdureza realizados na junta soldada, nas quatro condições de análise, onde se nota uma queda desta propriedade com o tempo de tratamento térmico. Adicionalmente, observou-se o maior valor de dureza para a linha de fusão na condição de como soldado.

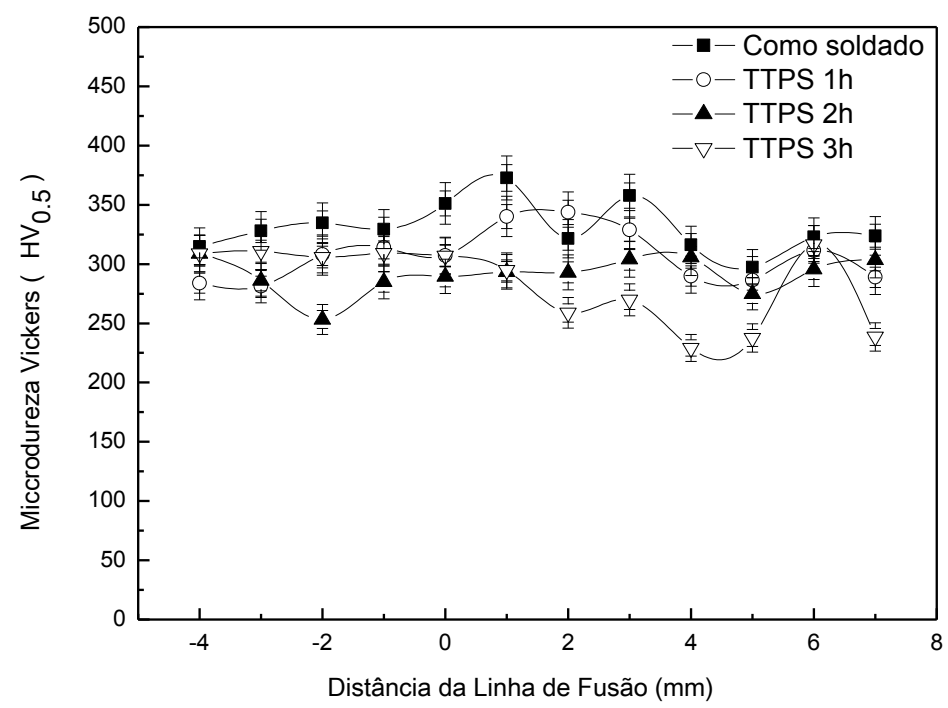

Figura 6. Variação da microdureza Vickers com o tempo de tratamento térmico.

\subsection{Ensaios Metalográficos da Junta Soldada}

A Figura 7 mostra a macrografia da junta soldada, onde se nota o aspecto da soldagem multipasse. Nota-se ainda o aspecto característico de aço fundido no metal base. A inspeção visual da seção macrográfica não revela a presença de descontinuidades.

\footnotetext{
* Contribuição técnica ao 69ำ Congresso Anual da ABM - Internacional e ao 14ํㅡㄹ ENEMET - Encontro Nacional de Estudantes de Engenharia Metalúrgica, de Materiais e de Minas,21 a 25 de julho de 2014, São Paulo, SP, Brasil.
} 


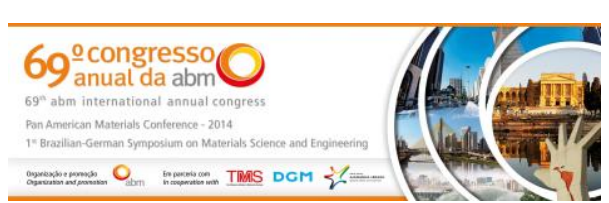

tendo apenas restrições aos teores máximos de fósforo e enxofre [18]. É de destaque neta Tabela, o Grau 115-85 que apresenta requisitos próximos daqueles exigidos pela norma IACS W22 [16] mostrada na Tabela 1 para o aço Grau R4, em relação ao limite de escoamento do material. No entanto, vale ressaltar que a grande diferença entre as duas normas é justamente o fato que a norma ASTM A 148 não faz menção específica à requisitos para ensaios de impacto Charpy- $V$, o que torna a utilização dos aços fundidos na aplicação de acessórios de ancoragem um novo desafio, por ter que cumprir este requisito adicional, para o qual as fundições normalmente não estavam habituadas.

Tabela 5. Propriedades mecânicas dos aços segundo a norma ASTM A 148 [18]

\begin{tabular}{c|c|c|c|c}
\hline Grau & LE (MPa) & LR (MPa) & $\mathrm{Al}(\%)$ & $\mathrm{RA}(\%)$ \\
\hline $80-40$ & 275 & 550 & 18 & 30 \\
\hline $80-50$ & 345 & 550 & 22 & 35 \\
\hline $90-60$ & 415 & 620 & 20 & 40 \\
\hline $115-85$ & 585 & 725 & 17 & 35 \\
\hline $115-95$ & 655 & 795 & 14 & 30 \\
\hline $130-115$ & 795 & 895 & 11 & 25 \\
\hline $135-125$ & 860 & 930 & 9 & 22 \\
\hline $150-135$ & 930 & 1035 & 7 & 18 \\
\hline
\end{tabular}

De fato, a Tabela 6 mostra algumas composições de aços fundidos especificados para aplicações estruturais [12-20], onde se percebe que a composição básica não envolve a adição do elemento níquel, sendo normal a utilização de aços C-Mn para esta aplicação, utilizando-se processamentos termomecânicos quando se precisa de propriedades mais elevadas [19]. Mesmo quando existe a preocupação de estruturas soldadas, as normas envolvidas [20-22] ou não especificam requisitos mandatórios de tenacidade ou permitem que os mesmos sejam acordados entre fornecedor e cliente, ou definem estes requisitos com valores muito inferiores aos previstos pela IACS W22 [16].

Tabela 6. Composição química de aços fundidos para diversas aplicações $[12,19,20]$.

\begin{tabular}{c|c|c|c|c|c|c|c|c|c|c|c}
\hline Material & $\mathrm{C}$ & $\mathrm{Mn}$ & $\mathrm{Si}$ & $\mathrm{Cr}$ & $\mathrm{Ni}$ & $\mathrm{Mo}$ & $\mathrm{P}$ & $\mathrm{S}$ & $\mathrm{V}$ & $\mathrm{Nb}$ & $\mathrm{Ti}$ \\
\hline A [ref.12]. & 0,24 & 1,37 & 0,38 & 0,40 & 0,47 & 0,18 & 0,03 & 0,03 & 0,008 & - & - \\
\hline B [ref.19]. & 0,17 & 1,20 & 0,47 & 0,10 & 0,02 & - & 0,01 & 0,01 & 0,01 & 0,02 & 0,02 \\
\hline $\begin{array}{c}\text { Grau WCC } \\
\text { [ref.20] }\left(^{*}\right)\end{array}$ & 0,25 & 1,20 & 0,60 & 0,50 & 0,50 & 0,20 & 0,04 & 0,04 & 0,03 & - & - \\
\hline $\begin{array}{c}\text { Grau 11Q } \\
\text { [ref.20](**) }\end{array}$ & $\begin{array}{c}015- \\
025\end{array}$ & $\begin{array}{c}040- \\
070\end{array}$ & $\begin{array}{c}020- \\
080\end{array}$ & - & $\begin{array}{c}1,65- \\
200\end{array}$ & $\begin{array}{c}020- \\
030\end{array}$ & 0,04 & 0,04 & - & - & - \\
\hline $\begin{array}{c}\text { Grau 340-550W } \\
\text { [ref.20](**) }\end{array}$ & 0,25 & 1,50 & 0,60 & 0,35 & 0,40 & 0,15 & 00,35 & 0,035 & 0,05 & - & - \\
\hline $\begin{array}{c}\text { Grau 620-820 } \\
\text { [ref.20](***) }\end{array}$ & - & - & 0,60 & - & - & - & 00,35 & 0,035 & - & - & - \\
\hline
\end{tabular}

(*) ASTM A 216/A 216M - 07; $\left(^{* *}\right)$ ASTM A 732/A 732M - 05; $\left(^{* * *}\right)$ ISO $3755-W$, faz mençao a soldabilidade; $\left({ }^{* \star * *}\right)$ ISO 9477.

Com o intuito de cumprir estes objetivos, algumas alterações de processos e, principalmente, de materiais foram necessárias, destacando-se uma análise criteriosa da composição química. Neste quesito, verifica-se uma opção por uma composição que permita uma temperabilidade elevada, mas mantendo um baixo teor de carbono e um teor elevado de níquel (Tabela 2), de forma a permitir a obtenção de elevada resistência mecânica e alta tenacidade ao impacto. Com base

\footnotetext{
* Contribuição técnica ao 69 Congresso Anual da ABM - Internacional e ao 14ํㅡㄹ ENEMET - Encontro Nacional de Estudantes de Engenharia Metalúrgica, de Materiais e de Minas,21 a 25 de julho de 2014, São Paulo, SP, Brasil.
} 
nestas características importantes, embora o aço fundido em estudo apresente um elevado carbono equivalente (Tabela 2), traz consigo uma possibilidade de apresentar uma boa soldabilidade pela sua composição base. Todas estas características foram muito importantes para as propriedades mecânicas obtidas, conforme já discutido em trabalho anterior [13].

No presente trabalho, conforme já abordado anteriormente, a questão crucial seria a avaliação da influência do tempo de tratamento térmico nas propriedades mecânicas do reparo soldado.

Neste aspecto, a comparação dos resultados nas diversas condições de análise da junta soldada, mostra não ter ocorrido uma variação significativa das propriedades mecânicas em função do aumento do tempo de revenido. Particularmente, a única diferença foi notada na resistência mecânica, a qual apresentou uma diminuição contínua com o aumento do tempo de tratamento, embora deva ser ressaltado que a diferença da condição de como soldado para a condição TTPS - 3h foi de apenas $5 \%$. Adicionalmente, é digno de menção o fato que todos os resultados foram superiores ao mínimo exigido para o aço grau R4, sendo ainda importante ressaltar que todos os corpos-de-prova romperam no metal base (Tabela 4).

Ainda em relação aos resultados dos ensaios de tração, considerando que a resistência mecânica para os tempos de tratamento de 2 e 3 horas ficaram muito próximos ao mínimo exigido (Tabela 4), entende-se que o tempo de tratamento mais recomendado seria de 1 hora.

A observação dos resultados dos ensaios de impacto mostrados na Figura 4, permite inferir que, de forma diferente do que ocorreu no ensaio de tração, além de não ocorrerem variações significativas de resultados entre as condições analisadas em função dos tratamentos térmicos, verificou-se que todos os resultados apresentaram-se muito superiores ao mínimo requerido para o aço R4.

O mesmo pode ser verificado na Figura 5, quando se analisa os resultados para a condição de tratado termicamente por 1 hora, condição de melhor desempenho no ensaio de tração, para as diferentes posições em relação da linha de fusão, que se apresentam uniforme em relação ao metal base.

Estes resultados de tenacidade ao impacto, ratificados pelos ensaios de dureza, podem ser atribuídos a questões microestruturais, pois em todas as posições analisadas, verificou-se a ocorrência de martensita revenida de baixo carbono (Figura 8), o que é um indicativo de boa tenacidade, como consequência da composição química do aço em estudo. De fato, é importante destacar na composição química a presença importante do elemento níquel (Tabela 1), o qual é adicionado como o principal elemento de liga para a melhoria da tenacidade [23] em aços utilizados para construção de cascos de submarinos [24,25], onde os requisitos de resistência e tenacidade são muito rigorosos. Neste aspecto, Bhadeshia [24] comenta em seu estudo que tanto os aços quanto os metais de solda com um balanço adequado de elementos de liga, principalmente, manganês e níquel, propiciam a obtenção de juntas soldadas de alta resistência e boa tenacidade, o que está de acordo com os resultados obtidos.

Finalmente, é importante destacar que esta alta temperabilidade é importante para a garantia da formação da martensita de boa tenacidade, mesmo em peças de grande espessura, onde a taxa de resfriamento é mais lenta, como no caso presente onde em passes intermediários se verificou $\Delta$ t8-5 da ordem de 16 segundos [26].

Considerando os resultados obtidos no aço em estudo, permite-se inferir que a adoção da soldagem como técnica de reparo de aços fundidos de elevada resistência mecânica, com composição química similar à utilizada no presente

\footnotetext{
* Contribuição técnica ao $69^{\circ}$ Congresso Anual da ABM - Internacional e ao 14ํㅡㄹ ENEMET - Encontro Nacional de Estudantes de Engenharia Metalúrgica, de Materiais e de Minas,21 a 25 de julho de 2014, São Paulo, SP, Brasil.
} 


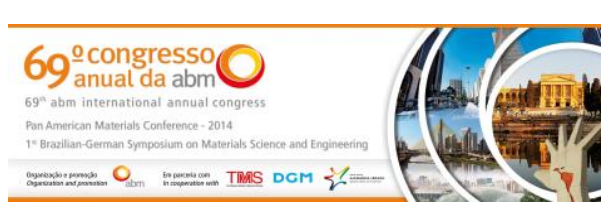

trabalho, não causa problemas nas propriedades mecânicas e, consequentemente, possibilita a execução de um reparo seguro para componentes de ancoragem, desde que se utilize um procedimento de soldagem adequado.

\section{CONCLUSÕES}

Do exposto no transcurso do presente trabalho, pode-se concluir que:

a) O aço fundido R4 estudado é soldável pelo processo eletrodo revestido com preaquecimento de $200^{\circ} \mathrm{C}$ e tratado termicamente a $600^{\circ} \mathrm{C}$ por 1 hora;

b) $\mathrm{O}$ aço fundido estudado apresentou pequena variação de propriedades com a mudança do tempo de tratamento e;

c) É recomendável a utilização de aços fundidos de alta resistência com baixo carbono e com adição de níquel em sua composição química, para obtenção de boas propriedades mecânicas na ZTA das juntas soldadas.

\section{Agradecimentos}

Os autores agradecem às seguintes Instituições pelo apoio prestado na execução do presente trabalho: CEFET-RJ, Fluke Engenharia Ltda., CNPq, e FINEP.

\section{REFERÊNCIAS}

1 Gonçalves RCF, Costa LCC. Inspeção em Linhas de Ancoragem de Unidades de Produção, Anais do XXI Congresso Nacional de Ensaios Não Destrutivos, 2002: 1-9.

2 Chave AP, Estudo comparativo da vida em fadiga de aços fundidos e forjados de alta resistência para utilização em acessórios de linhas de ancoragem de plataformas offshore, Dissertação de Mestrado, Rio de Janeiro, CEFET-RJ, 2010.

3 Pinheiro MM, Jorge JCF, Souza LFG e Bott IS. Efeito do tratamento térmico póssoldagem nas propriedades de metal de solda de alta resistência obtidos por arame tubular tipo metal cored, 7ํㅡㄹ Congresso Brasileiro de Engenharia de Fabricação, ABECM, Associação Brasileira de Engenharia e Ciências Mecânicas 2013.

4 Santos Filho AMF, Guimarães AS e Jorge JCF. Efeito do procedimento de soldagem nas propriedades mecânicas da ZTA de reparos em aço fundido (ASTM A27 Gr 60 30) pelo processo eletrodo revestido, Anais do $14^{\circ}$ Congresso Nacional de Transportes Marítimos e Construção Naval, 1992: 151-177.

5 Santos Filho AMF; Estudo sobre a zona termicamente afetada de reparos por soldagem em aço fundido de baixo teor de carbono pelo processo eletrodo revestido, Dissertação de Mestrado, Rio de Janeiro, 1992.

6 Santos Filho AMF, Guimarães AS e Jorge JCF. Uma avaliação da soldagem de aço fundido tipo C-Mn para indústria naval, Anais do XIX Encontro Nacional de Tecnologia da Soldagem, 1993: 273-288.

7 Jorge JCF, Santos Filho AMF e Vieira RD. Soldagem de reparo em aços fundidos de alta resistência e baixa liga. Anais do XX Encontro Nacional de Tecnologia da Soldagem, 1994: 307-320.

8 Mosciaro HB e Jorge JCF. Propriedades mecânicas de reparos por soldagem de aço fundido de alta resistência, Anais do XXI Encontro Nacional de Tecnologia da Soldagem, 1995: 307-317.

9 Mosciaro HB e Jorge JCF. Avaliação de procedimentos de reparos soldados para estruturas offshore em aços fundidos de alta resistência. Tecnologia e Cultura. 1997;1(1):41-45.

\footnotetext{
* Contribuição técnica ao $69^{\circ}$ Congresso Anual da ABM - Internacional e ao 14ํㅡㄹ ENEMET - Encontro Nacional de Estudantes de Engenharia Metalúrgica, de Materiais e de Minas,21 a 25 de julho de 2014, São Paulo, SP, Brasil.
} 


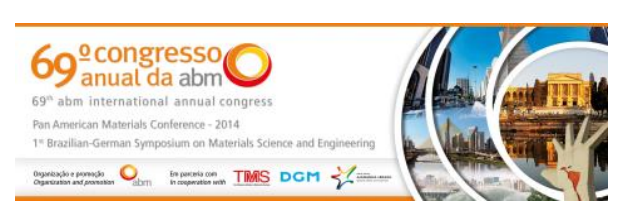

10 Vieira RD, Jorge JCF, Freire JLF e Castro JTP. Medição de tensões residuais em

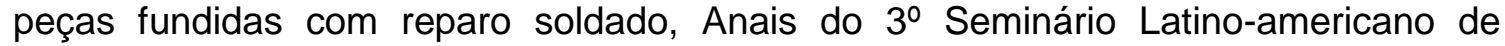
Inspeção de Equipamentos, 1995: 39-46.

11 Santos Filho OR, Santos Filho AMF, Vieira RD, Souza LFG, Pacheco PMCL, Jorge JCF. Avaliação de juntas soldadas de aços fundidos para construção naval, Anais do 14 ${ }^{\circ}$ Congresso Brasileiro de Engenharia e Ciência dos Materiais, 2000, 37901-37913.

12 Jorge JCF, Souza LFG, Santos Filho OR, Santos Filho AM, Bott IS, Guimarães FHB. Relação tenacidade/microestrutura da ZTA de aço fundido ASTM A $148 \mathrm{Gr}$. 80-50 para acessórios de ancoragem de plataformas de petróleo, Soldagem \& Inspeção, 2004; 9(4): 192-197.

13 Sumam JA, Jorge JCF, Souza LFG, Bott IS. Efeito de Tratamentos Térmicos pósSoldagem nas Propriedades de Aço Fundido de Elevada Resistência para Sistemas de Ancoragem de Plataformas Marítimas, Soldagem \& Inspeção, 2004; 9(4):205-212.

14 ABS, Guide for certification of offshore mooring chain, Section 3, Accessories, 2011.

15 Det Norske Veritas AS, DNV-OS-302, Offshore Mooring Chain, October, 2009.

16 International Association of Classification Societies, W22, Offshore Mooring Chain, June, 2011.

17 American Bureau of Shipping, Rules for Materials and Welding, Part 2, USA, 2012.

18 ASTM A 148, Standard Specification for Steel Castings, High Strength, for Structural Purposes, 2005.

19 Zhao,J, Jiang,Z, Lee, CS. Enhancing impact fracture toughness and tensile properties of a microalloyed cast steel by hot forging and post-forging heat treatment processes, Materials \& Design, 2013; :227-233.

20 Steel Founders' Society of America, Steel Castings Handbook, Supplement 2, Summary of Standard Specifications for Steel Castings, p.1-66, 2009.

21 Det Norske Veritas AS, Offshore Standard DNV-OS-F101, Submarine Pipeline Systems, August, 2012.

22 Marouco ES, Diniz JLC, Santos Filho OR, Souza LFG, Jorge JCF. Estudo do aporte térmico nas propriedades mecânicas de metais de solda de aço C-Mn obtidos pelo processo arco submerso, Tecnologia em Metalurgia, Materiais e Mineração, 2013; 10(2):128-137.

23 Roepke C, Liu S. Hybrid laser arc welding of HY-80 steel, Welding Journal, 2009;88(8):159-167.

24 Bhadeshia HKDH. Strong ferritic-steel welds, Materials Science Forum, 2007; 539-543: 6-11.

25 Lins Junior AS. Avaliação das propriedades mecânicas de juntas soldadas de aço HY80, Dissertação de Mestrado, Rio de Janeiro, CEFET-RJ, 2013.

26 EN 1011-2, Welding - Recommendations for welding of metallic materials - Part 2: Arc welding of ferritic steels, December, 2003.

\footnotetext{
* Contribuição técnica ao 69ำ Congresso Anual da ABM - Internacional e ao 14ํㅡㄹ ENEMET - Encontro Nacional de Estudantes de Engenharia Metalúrgica, de Materiais e de Minas,21 a 25 de julho de 2014, São Paulo, SP, Brasil.
} 